\title{
Manajemen Panen dan Pasca Panen Ubi Kayu (Manihot esculenta Crantz) untuk Bahan Baku Industri Tapioka di Lampung
}

\author{
Harvest and Post Harvest Management of Cassava (Manihot esculenta Crantz) to Suppy Raw Material \\ Tapioca Industry in Lampung
}

\author{
Elizabet Sagala dan Suwarto*
}

Departemen Agronomi dan Hortikultura, Fakultas Pertanian, Institut Pertanian Bogor (Bogor Agricultural University), Jl. Meranti, Kampus IPB Darmaga, Bogor 16680, Indonesia Telp.\&Faks.62-251-8629353 e-mail agronipb@indo.net.id *Penulis untuk korespondensi: wrtskm@yahoo.com

Disetujui 6 November 2017/Published online 14 November 2017

\begin{abstract}
The cassava production as raw material of tapioca still faced a lot of problem. Low production and nonperishable characteristic of cassava were two problem that must been solved. One of method for solfing this problem was good management for harvest and post harvest of cassava. This activity studied about harvest and post harvest management of cassava to supply raw material of tapioca. The purpose of this activity was direct studied about the technic, problem, and solution of harvest and post harvest of cassava. The primery and secodary data was taken during the research activity. The primary data was taken with direct observation and interview in the field. The secondary data was taken from archives of company. This activity showed that harvest and post harvest management was not good enough yet, because there ware underipe or overripe cassava, low skill of harvesters, and rotten cassava in the field.
\end{abstract}

Keywords : cassava, harvest management, postharvest management, raw material tapioca

\section{ABSTRAK}

Produksi singkong sebagai bahan baku tapioka masih menghadapi banyak masalah. Ciri produksi rendah dan mudah busuk dari singkong merupakan dua masalah yang harus dipecahkan. Salah satu metode untuk mengatasi masalah ini adalah pengelolaan panen dan panen ubi kayu yang baik. Kegiatan ini mempelajari tentang pemanenan dan pasca panen ubi kayu untuk memasok bahan baku tapioka. Tujuan dari kegiatan ini adalah studi langsung tentang teknik, masalah, dan pemecahan panen dan pasca panen dari singkong. Data primer dan sekunder diambil selama kegiatan penelitian. Data primer diambil dengan observasi langsung dan wawancara di lapangan. Data sekunder diambil dari arsip perusahaan. Kegiatan ini menunjukkan bahwa pengelolaan panen dan pasca panen belum cukup baik, karena di sana ada kekurangan atau singkong, rendahnya keterampilan pemanen, dan singkong busuk di lapangan.

Kata kunci : bahan baku tapioka, manajemen panen, manajemen pasca panen, singkong 


\section{PENDAHULUAN}

Ubi kayu merupakan tanaman penghasil karbohidrat yang memiliki peranan cukup penting. Ubi kayu tidak hanya sebagai sumber bahan pangan tetapi juga sebagai bahan baku industri, etanol, dan pakan temak (Kasim, 2009; Puspitasari, 2009; Costa, 2010).

Ubi kayu merupakan bahan pangan yang mudah rusak dan akan membusuk dalam 2 - 5 hari (Barrett dan Damardjati, 1984). Selain daya simpan yang singkat, susut saat panen dan pasca panen yang tinggi menjadi masalah. Diperkirakan susut pada saat panen ubi kayu sebesar $7 \%$ dan susut pasca panen lebih dari $24 \%$. Susut yang terjadi pada ubi kayu dapat disebabkan oleh faktor fisik, fisiologis, hama dan penyakit. Susut fisik dapat terjadi akibat kerusakan mekanis selama pemanenan dan penanganan, dan akibat perubahan suhu. Susut fisiologis terutama disebabkan oleh air, enzim dan respirasi. Sedangkan faktor hama dan penyakit mencakup mikro-organisme (jamur, bakteri, dan virus), insek, tikus, dan hama (Barret dan Damardjati, 1984). Sistem panen yang belum terstruktur juga menjadi masalah, dimana kadang terdapat ubi kayu yang sangat melimpah di pasaran dan kadang kebutuhan tidak tercukupi.

Kebutuhan ubi kayu setiap tahun selalu meningkat, baik untuk memenuhi kebutuhan dalam negeri maupun ekspor. Pada tahun 2004 sampai 2006 ekspor ubi kayu Indonesian semakin meningkat dari 53304 ton menjadi 139096 ton (Deptan, 2007). Tidak hanya ubi kayu, ekspor produk olahan ubi kayu seperti tapioka dan gaplek juga tinggi yaitu 6209.7 ton pada bulan Mei 2011. (Pusat Data dan Sistem Informasi Pertanian Kementerian Pertanian, 2011).

Ketersediaan bahan baku sangat diperlukan dalam industri tapioka. Apabila terjadi kelangkaan bahan baku maka produksi akan terhambat. Kualitas bahan baku juga sangat penting dalam industri tapioka karena kualitas bahan baku akan menentukan kualitas dari tepung tapioka yang dihasilkan. Untuk menghasilkan bahan baku tapioka yang berkualitas dengan kontinuitas yang terjamin dan dengan jumlah yang memadai diperlukan manajemen panen dan pasca panen yang baik.

Manajemen atau pengelolaan panen dan pasca panen merupakan semua kegiatan yang berkaitan dengan pelaksanaan panen dan pasca panen. Pengelolaan panen dapat dilaksanakan dengan pembentukan organisasi panen, penentuan kebutuhan tenaga kerja, penetapan kriteria panen, dan pengelolaan pengangkutan (Sulaiman, 2007).
Tujuan umum dari kegiatan penelitian ini adalah membandingkan pengetahuan yang diperoleh selama perkuliahan dengan keadaan nyata di lapangan dan menambah pengetahuan dan wawasan serta melatih penulis untuk mengikuti pekerjaan dalam proses kerja secara nyata, meningkatkan kemampuan teknis, manajerial, serta analisis kegiatan di lapangan. Tujuan khusus dari kegiatan penelitian ini adalah nntuk mempelajari manajemen panen dan pasca panen ubi kayu untuk bahan baku tapioka dan mempelajari secara langsung teknik-teknik, pemasalahan panen dan pasca panen ubi kayu serta solusinya.

\section{METODE PENELITIAN}

Kegiatan yang dilaksanakan selama penelitian meliputi pekerjaan teknis budidaya, manajerial kebun dan pengambilan data. Kegiatan dalam pengumpulan data meliputi pengambilan data primer dan data sekunder. Kegiatan penelitian ini juga dilakukan penulis secara langsung dengan mengikuti dan mempelajari seluruh kegiatan di lapang. Kegiatan sebagai asisten mandor selama empat minggu, asisten kepala divisi selama lima minggu, sebagai quality control selama dua minggu, asisten pengawas lapang kurang lebih empat minggu,dan mengikuti kegiatan tambahan dari perusahaan kurang lebih tiga minggu.

Penulis juga secara khusus melakukan kegiatan pengamatan yang berhubungan dengan panen dan pasca panen, yang meliputi :

1. Pengumpulan data panen berupa : kriteria panen ubi kayu, persiapan panen, tenaga kerja panen, peralatan panen, organisasi dan administrasi panen, pelaksaan panen, pemeriksaan kualitas panen, sistem panen, upah panen, pengangkutan hasil panen, kehilangan produksi (losses), dan pencapaian produksi. Data diperoleh dengan melakukan wawancara dan mengamati secara langsung di kebun PT PAL dan di kebun petani mitra. Pengamatan terhadap kriteria panen ubi kayu, berupa umur panen ubi kayu dan pengaruh penundaan umur panen terhadap bobot ubi kayu yang akan dipanen. Data diambil dari empat blok dengan dua umur panen yang berbeda. Dua blok untuk satu umur panen yang sama. Setiap blok diambil 1 ha, dalam satu hektar diambil lima baris dan dalam baris diambil 3 batang ubi kayu secara acak.

2. Pasca panen di kebun : Pengambilan data dilakukan dengan melakukan wawancara dan mengamati secara langsung kegiatan pasca panen di kebun. 
3. Pasca panen di pabrik

a. Kebutuhan bahan baku. Kebutuhan bahan baku akan dianalisis berdasarkan kebutuhan minimum pabrik

b. Lama penyimpanan ubi kayu di lapangan; pabrik akan mengolah ubi kayu apabila tercapai bobot 700 ton. Lama penyimpanan ubi kayu dicatat selama periode pengolahan 15 hari

c. Analisis bahan baku (pengukuran kadar aci dan rafaksi); pengukuran kadar aci dilakukan untuk membantu menetukan besarnya potongan bahan baku yang dibeli. Pengamatan terhadap pengukuran kadar aci dilakukan selama 1 hari dengan mengambil sampel dari bahan baku yang dibeli; rafaksi merupakan potongan bobot di pabrik karena adanya kotoran dan materi lain yang terbawa saat panen. Untuk analisis bahan baku yang diamati adalah persentasi rafaksi

Data sekunder diperoleh dari literatur dan laporan manajemen mengenai keadaan umum perusahaan, letak geografis, keadaan iklim dan tanah, luas areal penanaman, produksi, struktur organisasi (kelompok-kelompok tenaga kerja, deskripsi tugas, dan fungsi-fungsi manajemen), dan ketenagakerjaan.

Data primer dan data sekunder yang diperoleh dinalisis dengan menggunakan uji t dan secara kuantitatif (mencari rata-rata dan persentasi). Data diuraikan secara deskriptif dan dibandingkan terhadap norma baku yang berlaku pada perkebunan ubi kayu dan standar yang ditetapkan oleh perusahaan.

\section{HASIL DAN PEMBAHASAN}

\section{Keadaan Umum}

Penelitian dilaksanakan di Kecamatan Way Serdang, Kabupaten Mesuji, Lampung Timur. Varietas ubi kayu yang ditanam adalah varietas Kasetsart (UJ-5). Wilayah penelitian termasuk ke dalam klasifikasi iklim B dengan jenis tanah Ultisols dan Incepticols. Derajat kemasaman $(\mathrm{pH})$ berkisar 4.35 - 4.65 dengan ketinggian tempat 3-50 m dpl.

\section{Kriteria Panen}

Berdasarkan umur panen tanaman, varietas ubi kayu dikelompokkan menjadi tiga, yaitu varietas berumur genjah, dipanen pada umur 7 - 9 bulan, varietas berumur sedang pada umur 8 - 11 bulan, dan varietas berumur dalam pada umur
10 - 12 bulan (Wargiono et al., 2006; Tonglum at al., 2001).

Ubi kayu yang adalah UJ-5 (Kasetsart). Ubi kayu UJ-5 sebaiknya dipanen setelah berumur 9 - 10 bulan karena kandungan pati yang terkandung dalam umbi ubi kayu sudah maksimal, yaitu antara 19 - 30\% (Hafsah, 2003).

Tabel 1. Umur panen dan produktivitas ubi kayu

\begin{tabular}{|c|c|c|c|c|}
\hline \multicolumn{2}{|c|}{ Blok Waktu tanam } & $\begin{array}{l}\text { Waktu } \\
\text { panen }\end{array}$ & $\begin{array}{l}\text { Umur } \\
\text { panen } \\
\text { (bulan) }\end{array}$ & $\begin{array}{l}\text { Produkt } \\
\text { ivitas- }\end{array}$ \\
\hline \multirow{3}{*}{ A 20} & November & Februari & & \\
\hline & 2009 & 2011 & 15 & 30.01 \\
\hline & November & Februari & & \\
\hline \multirow[t]{3}{*}{ A4 } & 2009 & 2011 & 15 & 20.59 \\
\hline & Rata-rata & & & 25.30 \\
\hline & Desember & & & \\
\hline \multirow[t]{2}{*}{ B13 } & 2009 & April 2011 & 16 & 20.24 \\
\hline & Desember & & & \\
\hline B14 & 2009 & April 2011 & 16 & 22.90 \\
\hline B15 & $\begin{array}{c}\text { Desember } \\
2009 \\
\text { Desember }\end{array}$ & April 2011 & 16 & 18.79 \\
\hline B16 & $\begin{array}{c}2009 \\
\text { Desember }\end{array}$ & April 2011 & 16 & 18.30 \\
\hline B17 & $\begin{array}{c}2009 \\
\text { Rata-rata }\end{array}$ & April 2011 & 16 & $\begin{array}{l}23.22 \\
20.69\end{array}$ \\
\hline B9 & $\begin{array}{c}\text { November } \\
2009 \\
\text { Rata-rata } \\
\text { November }\end{array}$ & April 2011 & 17 & $\begin{array}{l}14.75 \\
14.75\end{array}$ \\
\hline B1 & $\begin{array}{c}2009 \\
\text { November }\end{array}$ & Mei 2011 & 18 & 19.54 \\
\hline B2 & $\begin{array}{c}2009 \\
\text { November }\end{array}$ & Mei 2011 & 18 & 23.85 \\
\hline \multirow[t]{3}{*}{ B3 } & 2009 & Mei 2011 & 18 & 29.29 \\
\hline & Rata-rata & & & 24.23 \\
\hline & Rata-rata total & & & 22.27 \\
\hline
\end{tabular}

Ubi kayu dipanen lebih dari 12 bulan. Hal ini dilakukan untuk mendapatkan bobot ubi segar yang lebih tinggi (Tonglum at al., 2011). Perbedaan umur panen sendiri disebab-kan oleh sulitnya mendapatkan tenaga kerja panen, curah hujan yang tinggi, terbatasnya angkutan panen, dan kendala dalam pembagian tugas antara kebun ubi kayu dengan kelapa sawit.

Dari Tabel 1 dapat dilihat bahwa produktivias ubi kayu ubi kayu dipanen pada umur 15 bulan lebih tinggi dibanding dengan ubi kayu yang dipanen dengan umur 16, 17, dan 18 bulan. Hal ini menunjukkan bahwa penundaan umur panen tidak meningkatkan produktivitas ubi kayu. Untuk lebih lanjut dilakukan pengamatan berdasarkan bobot pertanaman dan diperoleh bahwa penundaan panen ubi kayu di tidak berbeda nyata terhadap bobot ubi kayu yang dipanen pada umur 16 dan 18 bulan (Tabel 2). Hal ini 
disebabkan berbagai faktor seperti, setelah ubi kayu berumur 9 bulan maka tidak dipelihara lagi sehingga ubi kayu bersaing dengan gulma, umbi busuk, dan adanya area yang tergenang air.

Tabel 2. Rata-rata bobot ubi kayu pada umur panen 16 dan 18 bulan

\begin{tabular}{|c|c|c|c|}
\hline $\begin{array}{l}\text { Umur } \\
\text { panen }\end{array}$ & Blok & $\begin{array}{c}\text { Jumlah tanaman } \\
\text { sampel }\end{array}$ & $\begin{array}{c}\text { Rata-rata } \\
\text { bobot/tanaman }\end{array}$ \\
\hline 16 & B2, B3 & 30 & $3.425 \mathrm{a}$ \\
\hline 18 & B 14, B 15 & 30 & $3.055 \mathrm{a}$ \\
\hline
\end{tabular}

Kadar pati ubi kayu tidak menurun meski panen ditunda beberapa bulan setelah fase kadar pati optimal, bahkan hasil pati meningkat karena bobot ubi cenderung meningkat dengan bertambahnya umur tanaman (Wargiono et al., 2006). Kadar pati ubi kayu yang di panen pada umur 15 - 18 bulan adalah 24\%. Ubi kayu varietas Kasetsart sendiri jika dipanen pada umur panen yang tepat ( 9 - 11 bulan) menghasilkan kadar aci 19 - 30\% (Hafsah, 2003).

Ubi kayu yang dipanen pada kebun petani mitra biasanya berumur 9 - 12 bulan (Tabel 1). Pada kondisi tertentu, pemanenan sering ditunda. Penundaan umur panen menjadi lebih lama biasanya disebabkan karena faktor cuaca dan harga. Pada saat curah hujan tinggi akan menyebabkan jalan menjadi rusak sehingga waktu panen harus ditunda. Sebaliknya jika curah hujan terlalu rendah dapat menyebabkan tanah menjadi sangat keras, sehingga menyulitkan pemanenan. Jika harga jual rendah, beberapa petani biasanya akan menunda pemanenan sampai dengan harga jual kembali tinggi.

Pemanenan ubi kayu sering juga dilakukan petani mitra lebih awal. Hal ini disebabkan oleh kebutuhan yang mendesak. Pada umumnya terjadi sebelum lebaran dan awal semester. Pemanenan pada umur muda akan berpengaruh pada besarnya potongan di pabrik. Faktor harga dan menghindari gagal panen juga menjadi faktor panen sebelum waktunya.

Hasil pengamatan pada Tabel 3 menunjukkan bahwa, 20\% petani yang melakukan panen lebih awal yaitu 7 bulan, sedangkan petani yang lain melakukan panen sesuai dengan kriteria panen UJ-5. Dari hasil panen yang diperoleh, ubi kayu yang dipanen pada umur 7 bulan memiliki produktivitas yang lebih tinggi jika dibandingkan dengan ubi kayu yang dipanen pada umur 8,9 , 10,dan 11 bulan, sedangkan pemanenan pada umur 12 bulan memiliki tingkat hasil yang paling tinggi.

Perbedaan hasil panen pada petani mitra disebakan oleh berbagai faktor, seperti teknik budidaya, jarak tanam dan kesuburan tanah. Jarak tanam akan memepengaruhi populasi tanaman dalam luasan tertentu. Pada umunya petani mitra menanam ubi kayu lebih rapat. Seperti ubi kayu petani mitra yang berada di Palembang, lokasi penanaman ubi kayu merupakan bukaan hutan sehingga tanahnya masih subur.

Tabel 3. Umur panen dan produktivitas ubi kayu petani mitra

\begin{tabular}{llcc}
\hline No & Lokasi & $\begin{array}{c}\text { Umur panen } \\
\text { (bulan) }\end{array}$ & $\begin{array}{c}\text { Produktivitas } \\
\text { (ton/ha) }\end{array}$ \\
\hline 1 & Bandar Jaya & 7 & 25 \\
2 & Mataram Jaya & 7 & 20 \\
3 & Bandar Sakti & 7 & 30 \\
& Rata-rata & & 25 \\
& Bandar & 8 & 18 \\
4 & Mataram & 8 & 22 \\
5 & SP ${ }_{3}$ D & & 20 \\
& Rata-rata & 9 & 25 \\
6 & Metro Kibang & 9 & 25 \\
7 & Bandar Rejo & & \\
& Bandar & 9 & 25 \\
8 & Mataram & 9 & 25 \\
9 & Rojo Mulio & 9 & 23 \\
10 & Menggala & & 24.6 \\
& Rata-rata & 10 & 20 \\
11 & OKI & 10 & 15 \\
12 & Gedung Boga & & 17.5 \\
& Rata-rata & 11 & 20 \\
13 & SPUA & 11 & 18 \\
14 & SP ${ }_{5}$ A & & 19 \\
& Rata-rata & 12 & 35 \\
15 & Palembang & & 35 \\
& Rata- rata & & 23.73 \\
\hline & Rata-rata total & & \\
\hline
\end{tabular}

Persiapan panen. Persiapan panen ubi kayu berupa persiapan penyediaan tenaga kerja dan angkuatan sedangkan persiapan panen untuk petani mitra berupa persiapan area panen, tenaga kerja, dan angkutan panen. Persiapan area panen berupa penyemprotan gulma dengan mengunakan Round up atau Clean up dengan dosis 4 l/ha. Banyaknya perusahaan di lingkungan sekitar petani mitra menyebabkan petani mitra kesulitan dalam mempersiapkan tenaga kerja panen meskipun upah yang diberikan oleh petani mitra lebih besar dibanding di perusahaan-perusahaan. Persiapan angkutan juga sangat sulit, karena pemanenan sering pada waktu yang bersamaan.

Peralatan panen. Alat-alat panen yang digunakan di kebun adalah bajak panen, parang, karung, angkutan (truck, trailler, dum truck), dan 
batu asah. Penggunaan bajak panen bertujuan untuk mempercepat pemanenan dan mempermudah panen. Kelemahan dari bajak panen adalah ubi kayu banyak yang terpotang. Ubi kayu yang terpotong akan cepat membusuk jika tidak segera diolah. Bajak panen dalam 1 HKM dapat membajak area seluas 3 ha. Alat panen yang digunakan di kebun mitra sendiri adalah parang, karung, batu asah, gancu, angkutan , dan cangkul.

Tenaga kerja dan kapasitas panen. Tenaga kerja yang terbatas menyebabkan pemanenan ubi kayu sering terlambat. Rata-rata tenaga kerja panen yang digunakan adalah 17 orang pemanen. Jika dilihat berdasarkan kemampuan bajak panen dan tenaga kerja panen di lapangan, maka 17 orang tenaga kerja panen tidak optimal dalam pemanenan.

Kebutuhan tenaga kerja $=\frac{\text { luas area } x \text { produktivitas }}{\text { kemampuan panen }}=\frac{2 \times 22.27}{921.38}$

$$
=72.5=73 \text { orang }
$$

Jika dilihat berdasarkan standar perusahaan dimana $1 \mathrm{HK}=2$ ton, maka kebutuhan tenaga kerja adalah 35 orang.

Tabel 4. Ketersediaan tenaga kerja dan kapasitas panen pemanen ubi kayu 2011

\begin{tabular}{lcrrrr}
\hline No Tanggal & $\begin{array}{c}\text { Laki- } \\
\text { laki } \\
\text { (orang) }\end{array}$ & $\begin{array}{c}\text { Wanit } \\
\text { (orang) }\end{array}$ & $\begin{array}{c}\text { TTenag } \\
\text { a kerja } \\
\text { (orang) }\end{array}$ & $\begin{array}{c}\text { Rata-rata } \\
\text { (kg/orang/ hari) }\end{array}$ \\
\hline 1 & 9 April & 9 & 13 & 22 & 659.09 \\
2 & 11 April & 3 & 1 & 4 & 1795.00 \\
3 & 12 April & 4 & 9 & 13 & 878.46 \\
4 & 13 April & 3 & 1 & 4 & 1575.00 \\
5 & 14 April & 4 & 10 & 14 & 970.00 \\
6 & 15 April & 3 & 4 & 7 & 842.86 \\
7 & 16 April & 1 & 9 & 10 & 697.00 \\
8 & 12 Mei & 6 & 9 & 15 & 170.67 \\
9 & 13 Mei & 11 & 13 & 24 & 824.58 \\
10 & 14 Mei & 11 & 12 & 23 & 722.61 \\
11 & 15 Mei & 8 & 4 & 11 & 1484.55 \\
12 & 16 Mei & 13 & 9 & 22 & 1064.09 \\
13 & 17 Mei & 10 & 11 & 21 & 844.29 \\
14 & 18 Mei & 8 & 8 & 16 & 1310.63 \\
15 & 19 Mei & 10 & 10 & 20 & 902.50 \\
\hline & Rata-rata & 6.93 & 8.20 & 15.07 & 921.33 \\
\hline \multicolumn{5}{c}{} &
\end{tabular}

Kemampuan tenaga kerja dalam pemanenan ubi kayu rata-rata untuk panen bajak yaitu $921.33 \mathrm{~kg} /$ orang/hari. Hasil ini jauh dari standar perusahaan dimana kapasitas panen dapat mencapai $2-2,5$ ton/HK untuk wanita dan 2,5-3 ton/HK untuk tenaga kerja pria. Jika hasil yang diperoleh hanya $921.33 \mathrm{~kg} /$ orang/hari, maka upah yang diperoleh untuk pemanen adalah Rp. 32246. Sedangkan untuk mencapai $1 \mathrm{HK}$, maka hasil minimal yang harus dipanen BHL adalah 978 $\mathrm{kg} /$ orang.

Tidak tercapainya target panen disebabkan faktor transportasi dan cuaca.Transportasi panen yang terbatas, mengakibatkan setiap rombongan harus saling menunggu. Jumlah pemanen tidak sama setiap hari untuk setiap rombongan, pemanen enggan untuk memanen untuk diangkut keesokan harinya karena menyulitkan dalam pembagian upah. Curah hujan yang tinggi mengakibatkan umbi tertimbun dan tanah menjadi berlumpur sehingga pemanen sulit berjalan di area.

Pengaruh usia, jenis kelamin dan pengalaman kerja pada pemanenan tidak dapat dianalisis karena hasil panen dimasukkan pada satu rombongan. Pembagian hasil dilakukan secara merata. Hal ini dapat mengakibatkan sebagian BHL tidak bekerja maksimal. Maka diperlukan ketegasan dari ketua rombongan dan pengawasan yang baik dari mandor sangat.

Tabel 5. Ketersediaan tenaga kerja dan kapasitas panen ubi kayu pada petani mitra

\begin{tabular}{clccc}
\hline No & \multicolumn{1}{c}{ Lokasi } & $\begin{array}{c}\text { Tenaga } \\
\text { kerja } \\
\text { (orang) }\end{array}$ & Rombon & $\begin{array}{c}\text { Rata-rata } \\
\text { (kg/orang/hari) }\end{array}$ \\
\hline 1 & Gedung Boga & 6 & 1 & 833.33 \\
2 & SP ${ }_{3}$ D & 6 & 1 & 1666.67 \\
3 & SPUA & 6 & 1 & 1166.67 \\
4 & Rojo Mulio & 7 & 1 & 1428.57 \\
5 & SP $_{5}$ A & 6 & 1 & 916.67 \\
6 & Bandar jaya & 8 & 1 & 2000.00 \\
7 & Mataram Jaya & 8 & 1 & 1000.00 \\
8 & Metro Kibang & 10 & 1 & 1500.00 \\
9 & Bandar Rejo & 8 & 1 & 1875.00 \\
10 & Bandar Sakti & 8 & 1 & 2500.00 \\
& Bandar & & 1 & 875.00 \\
11 & Mataram & 8 & 1 & \\
& Bandar & 6 & 1 & 1166.67 \\
12 & Mataram & 6 & 1 & 1666.67 \\
13 & OKI & & & \\
14 & Palembang & 6 & 1 & 1166.67 \\
15 & Menggala & 6 & 1 & 1333.33 \\
\hline & Rata-rata & 7 & 1 & 1406.35 \\
\hline
\end{tabular}

Kemampuan tenaga kerja panen ubi kayu petani mitra lebih tinggi jika dibandingkan dengan BHL PT PAL. Kapasitas panen BHL petani mitra berkisar $833.33-2500 \mathrm{~kg} / \mathrm{hari}$, dengan rata-rata kapasitas panen $1406.35 \mathrm{~kg} / \mathrm{hari}$.

Organisasi dan administrasi panen. Seorang mandor panen ubi kayu membawahi mandor harian. Mandor harian bertugas dalam mengawasi BHL. Ketua rombongan bersifat tetap. 
Ketua rombongan juga bertugas dalam membantu mandor dalam membuat laporan harian yang berisi jumlah tenaga kerja panen yang hadir. Laporan harian yang telah dibuat oleh mandor harian diserahkan kepada mandor panen. Laporan harian tersebut kemudian diserahkan kepada kepala divisi yang nantinya akan diserahkan kepada bagian administrasi dan keuangan. Upah BHL ditulis di debet order (DO). Debet order akan diserahkan kepada supir angkutan panen untuk digunakan di pabrik. Pihak pabrik akan mengisi bobot umbi yang dipanen berdasarkan hasil timbangan. DO tersebut akan diambil oleh admin PT PAL untuk pembayaran upah BHL.

Pelaksanaan panen. Pemanen dimulai dengan kegiatan pembajakan. Kegiatan panen dimulai pukul 07.00 WIB. Beberapa tenaga kerja mengumpulkan ubi kayu, eberapa BHL lainnya bertugas melakukan pemisahan ubi dari bonggol (penyecekan), kemudian dimasukkan ke dalam angkutan. Pada saat pelaksanaan panen, ubi kayu yang telah dibajak tidak langsung dikumpulkan, demikian juga ubi yang telah dikumpulkan tidak langsung diangkut ke pabrik. Hal ini akan mengakibatkan tingginya tingkat kehilangan hasil (losses). Pemanenan tanpa langsung diangkut akan mengakibatkan ubi kayu kepoyongan. Kepoyongan dapat menyebabkan rendemen pati ubi kayu mengalami penurunan $11-38 \%$ (Soeharmadani, 1990). Dengan menurunnya kadar aci maka potongan di pabrik akan semakin besar.

Data di atas menunjukkan bahwa pelaksanaan panen pada bulan Mei lebih baik dibanding dengan pelaksanaan panen pada bulan April. Terdapat ubi kayu yang dipanen pada bulan April yang diangkut 5 hari setelah bajak panen. Ubi kayu sendiri mudah rusak dan akan membusuk dalam 2 - 5 hari (Barrett dan Damardjati, 1984). Ubi kayu yang tidak langsung diangkut seperti pada bulan April disebabkan oleh berbagai faktor seperti :

1. Terbatasnya angkutan panen; dimana angkutan panen juga digunakan untuk mengangkut sawit

2. Hujan; karena pengangkutan ubi kayu dilakukan dengan memasukkan angkutan panen sampai ke dalam area, maka pada saat hujan angkutan sulit bergerak di area

3. Lama pemasukan ke dalam angkutan panen; waktu yang dibutuhkan untuk memasukkan ubi kayu lebih lama dibandingkan dengan sawit mengakibatkan supir angkutan kurang berkenan mengangkut ubi kayu

Pemanen di petani mitra dilakukan dengan cara dicabut. Ubi kayu dicabut lalu diletakkan pada satu tumpukan yang berada pada satu baris. Setelah dikumpulkan lalu dilakukan penyecekan kemudian dimasukkan kedalam truck.
Pemeriksaan kualitas panen. Pemeriksaan kualitas panen bertujuan untuk menjaga agar kegiatan panen berlangsung dengan baik dan mencegah kecurangan saat panen. Adapun hal yang menjadi perhatian dalam pengawasan dan pemeriksaan kualitas panen ubi kayu adalah :

1. Ubi kayu yang tertinggal di area. Biaya leles yang lebih tinggi dibandingkan biaya panen menyebabkan pekerja sering dengan sengaja meninggalkan ubi kayu di area agar hasil lelesan nantinya menjadi banyak

2. Bonggol ubi kayu dan tanah. BHL sering memasukkan bonggol dan tanah ke dalam angkutan dengan tujuan agar hasil panen tinggi

3. Proses kerja. Sarana transportasi yang terbatas dan pemanenan dengan sistem rombongan menyebabkan perlu pengawasan kerja agar rombongan lain tidak terlalu lama mengantri angkutan

Pengawasan di kebun petani mitra dilakukan secara kekeluargaan. Hal ini mengakibatkan ubi kayu hasil panen beberapa petani mitra memiliki kualitas yang rendah. Salah satu cara yang dapat dilakukan untuk mengatasi permasalahan yang ada adalah dengan memperketat pengawasan dan memberi peringatan kepada pemanen yang melakukan kecurangan.

Sistem panen. Sistem panen yang digunakan adalah sistem tonase. Kelebihan dari sistem ini adalah pemanen akan berusaha memanen sebanyak mungkin dan dapat mengurangi biaya panen. Kelemahan dari sistem ini adalah banyak ubi kayu yang tertinggal di area. Hasil panen dari setiap rombongan pada sistem tonase akan dipisah antara satu rombongan dengan rombongan lainnya sehingga ketika pemanenan dalam satu area dilakukan oleh beberapa rombongan maka dibutuhkan transportasi panen sesuai dengan jumlah rombongan. Hal ini sangat menyulitkan, mengingat transportasi tidak hanya digunakan untuk kebun ubi kayu saja tetapi juga untuk kebun kelapa sawit. Dengan menggunakan sistem ini, hendaknya diikuti dengan ketersediaan angkutan dan pengawasan yang lebih ketat.

Upah panen. Upah panen di kebun disesuaikan dengan hasil yang diperoleh BHL. Upah panen cabut sebesar Rp. 45 000/ton sedangkan untuk panen bajak Rp. 35 000/ ton. Namun untuk situasi tertentu (hujan) yang mengakibatkan BHL memasukkan ubi kayu ke dalam truck dengan cara langsir, BHL diberi tambahan upah Rp. 5 000/ton, sehingga upah panen cabut Rp 50 000/ton dan untuk panen bajak Rp. 40 000/ton. Selain upah panen terdapat juga upah leles, yaitu Rp. 75 000/ton - Rp. 130 
000/ton. Perbedaan upah leles tergantung dengan kondisi area. Semakin banyak ubi yang masih teringgal di area maka upah leles semakin murah dan begitu juga sebaliknya. Upah untuk panen cabut di kebun mitra adalah Rp 45 000/ton - Rp. 85 000/ton. Perbedaan upah tergantung kesepakatan dengan pemanen, wilayah, dan kondisi area panen. Kondisi arean panen yang banyak gulma akan mengakibatkan biaya cabut lebih mahal. Upah panen untuk satu wilayah berbeda dengan wilayah lainnya tergantung standar upah BHL masing-masing wilayah. Sedangkan upah untuk leles yaitu Rp. 100 000/ton.

Pengangkutan hasil panen. Pengangkutan hasil panen sangat penting saat panen ubi kayu. Sifat ubi kayu yang mudah busuk dan sistem panen yang bersifat tonase menyebabkan angkutan panen harus ada saat panen. Pengangkutan hasil dari kebun petani mitra sering tidak lancar. Hal ini disebabkan oleh kondisi jalan yang sangat buruk dan lokasi yang sangat jauh.

Kehilangan hasil (Losses). Memperkecil losses merupakan salah satu cara untuk meningkatkan produksi. Terdapat beberapa sumber losses di kebun. Area penanaman ubi kayu yang semakin sempit sehingga perhatian untuk ubi kayu semakin minim. Ubi kayu dipanen melebihi batas umur panen yang dianjurkan membuat ubi kayu banyak yang busuk. Kondisi cuaca yang tidak beraturan mengakibatkan panen tetap dilakukan saat hujan. Selang waktu antara bajak panen dengan pengumpulan dan pengangkutan yang terlalu lama mengakibatkan penyusutan bobot umbi terutama pada saat kemarau sedangkan pada musim hujan mengakibatkan umbi cepat busuk. Panen menggunakan bajak mengakibatkan banyak umbi yang terpotong. Umbi yang terpotong menjadi kecil biasanya tidak dipungut. Semakin banyak ubi terpotong maka losses akan semakin besar. Kehilanganm hasil biasanya terjadi di kebun adalah akibat ubi kayu terlalu lama di lapangan. Semakin lama ubi kayu dibiarkan di lapang, maka semakin besar losses yang ditimbulkan (Tabel 6). Berdasarkan pengamatan diperoleh bahwa ubi kayu dibiarkan selama tujuh hari setelah panen (HSP), maka ratarata penurunan bobot mencapai $0.59 \mathrm{~kg} /$ tanaman atau setara dengan $1313.93 \mathrm{~kg} / \mathrm{ha} \quad(5.9 \%)$. Kehilangan hasil juga dapat ditimbulkan karena adanya pencurian dari area. Untuk itu, selama panen hendaknya dilakukan pengawasan di area pemanenan.
Tabel 6. Penurunan bobot ubi kayu

\begin{tabular}{|c|c|c|c|c|c|c|c|}
\hline No. & $\begin{array}{c}1 \mathrm{HSP} \\
(\mathrm{kg})\end{array}$ & $\begin{array}{c}2 \text { HSP } \\
(\mathrm{kg})\end{array}$ & $\begin{array}{c}3 \text { HSP } \\
(\mathrm{kg})\end{array}$ & $\begin{array}{c}4 \text { HSP } \\
(\mathrm{kg})\end{array}$ & $\begin{array}{c}5 \text { HSP } \\
(\mathrm{kg})\end{array}$ & $\begin{array}{c}6 \text { HSP } \\
(\mathrm{kg})\end{array}$ & $\begin{array}{c}7 \text { HSP } \\
(\mathrm{kg})\end{array}$ \\
\hline 1 & 0.01 & 0.04 & 0.16 & 0.19 & 0.22 & 0.24 & 0.25 \\
\hline 2 & 0.18 & 0.32 & 0.42 & 0.43 & 0.44 & 0.52 & 0.56 \\
\hline 3 & 0.23 & 0.28 & 0.36 & 0.38 & 0.40 & 0.46 & 0.50 \\
\hline 4 & 0.70 & 0.72 & 0.83 & 0.87 & 0.91 & 0.94 & 0.97 \\
\hline 5 & 0.01 & 0.03 & 0.12 & 0.17 & 0.18 & 0.19 & 0.22 \\
\hline 6 & 1.05 & 1.11 & 1.30 & 1.35 & 1.52 & 1.66 & 1.75 \\
\hline 7 & 0.01 & 0.07 & 0.09 & 0.09 & 0.12 & 0.22 & 0.26 \\
\hline 8 & 0.54 & 0.58 & 0.61 & 0.63 & 0.65 & 0.68 & 0.73 \\
\hline 9 & 0.14 & 0.17 & 0.19 & 0.22 & 0.28 & 0.29 & 0.34 \\
\hline 10 & 0.03 & 0.13 & 0.18 & 0.23 & 0.31 & 0.34 & 0.36 \\
\hline 11 & 0.16 & 0.18 & 0.34 & 0.39 & 0.46 & 0.54 & 0.66 \\
\hline 12 & 0.20 & 0.30 & 0.40 & 0.44 & 0.55 & 0.65 & 0.70 \\
\hline 13 & 0.05 & 0.09 & 0.10 & 0.17 & 0.20 & 0.26 & 0.27 \\
\hline 14 & 0.20 & 0.30 & 0.39 & 0.42 & 0.48 & 0.53 & 0.56 \\
\hline 15 & 0.37 & 0.45 & 0.46 & 0.50 & 0.60 & 0.68 & 0.72 \\
\hline $\begin{array}{l}\text { Rata- } \\
\text { rata }\end{array}$ & 0.26 & 0.32 & 0.40 & 0.43 & 0.49 & 0.55 & 0.59 \\
\hline $1 \mathrm{ha}$ & 579.02 & 712.64 & 890.80 & 957.61 & 1091.23 & 1224.85 & 1313.93 \\
\hline
\end{tabular}

Kehilangan produksi untuk sebagian petani mitra juga tinggi. Kehilangan hasil tinggi terjadi jika tidak dilakukan pelelesan (Tabel 7).

Tabel 7. Pelaksanaan leles petani mitra

\begin{tabular}{|c|c|c|c|c|}
\hline No & Lokasi & $\begin{array}{c}\text { Tidak } \\
\text { dileles/dileles } \\
\end{array}$ & $\begin{array}{l}\text { Produkti } \\
\text { vitas }\end{array}$ & $\begin{array}{l}\text { Losse } \\
\text { S (\%) }\end{array}$ \\
\hline 1 & Gedung Boga & $\begin{array}{l}\text { Leles : } 400 \\
\mathrm{~kg} / \mathrm{ha}\end{array}$ & 15 & 2.67 \\
\hline 2 & SP3D & $\begin{array}{l}\text { Tidak dileles } \\
\text { Leles : } 500\end{array}$ & 22 & - \\
\hline 3 & SPUA & $\begin{array}{l}\mathrm{kg} / \mathrm{ha} \\
\text { Leles : } 400\end{array}$ & 20 & 2.5 \\
\hline 4 & Rojo Mulio & $\mathrm{kg} / \mathrm{ha}$ & 25 & 1.6 \\
\hline 5 & $\mathrm{SP}_{5} \mathrm{~A}$ & Tidak dileles & 18 & - \\
\hline 6 & Bandar Jaya & $\begin{array}{l}\text { Tidak di leles } \\
\text { Leles : } 1000\end{array}$ & 25 & - \\
\hline 7 & Mataram Jaya & $\begin{array}{l}\mathrm{kg} / \mathrm{ha} \\
\text { Leles : } 1000\end{array}$ & 20 & 5 \\
\hline 8 & Metro Kibang & $\mathrm{kg} / \mathrm{ha}$ & 25 & 4 \\
\hline 9 & Bandar Rejo & Tidak dileles & 25 & - \\
\hline 10 & $\begin{array}{l}\text { Bandar Sakti } \\
\text { Bandar }\end{array}$ & Tidak dileles & 30 & - \\
\hline 11 & $\begin{array}{l}\text { Mataram } \\
\text { Bandar }\end{array}$ & Tidak dileles & 18 & - \\
\hline 12 & Mataram & $\begin{array}{l}\text { Tidak dileles } \\
\text { Leles : } 1000\end{array}$ & 25 & - \\
\hline 13 & OKI & $\mathrm{kg} / \mathrm{ha}$ & 20 & 5 \\
\hline 14 & Palembang & Tidak dileles & 35 & - \\
\hline 15 & Menggala & Tidak dileles & 23 & - \\
\hline
\end{tabular}

Data yang diperoleh menunjukkan bahwa hanya $40 \%$ petani mitra yang melakukan 
pelelesan. Adanya petani mitra yang tidak melakukan pelesan adalah karena kurangnya tenaga kerja dan dikarenakan biaya leles yang lebih tinggi dibanding panen. Kehilangan hasil pada petani mitra akibat tidak melaksanakan leles mencapai 5\% dari hasil panen.

Pencapaian produksi. Pencapaian produksi merupakan jumlah nyata produksi yang ingin dicapai oleh suatu perusahaan. Produksi ubi kayu dipengaruhi oleh beberapa faktor, seperti jumlah tanaman/hektar, kondisi tanah, bahan tanam, teknik budidaya dan faktor luar seperti pencurian. Jika :

1. Jarak tanam ubi kayu $90 \mathrm{~cm} \times 60 \mathrm{~cm}$

Populasi tanaman $/ \mathrm{ha}=18$ 518/ha

2. Luas area produktif adalah $95 \%$

Populasi tanaman 17592 tanaman/ha

3. Tanaman yang berhasil tumbuh $90 \%$

Populasi tanaman adalah 15833 tanaman/ha

4. perkiraan bobot umbi yang dipanen

(berdasarkan bobot rata-rata Tabel 8) adalah :

Blok B2 = 15833 tanaman $\times 3.08$

$\mathrm{kg} / \mathrm{tanaman}$

$\begin{array}{ll}\text { ha }^{-1} & =48765.64 \mathrm{~kg} \mathrm{ha}^{-1}=48.76 \text { ton } \\ \text { Blok B3 } & =59.69 \text { ton ha }^{-1} \\ \text { B14 } & =49.56 \text { ton ha } \\ \text { B15 } & =47.18 \text { ton ha }\end{array}$

Potensi hasil varietas Kasetsart adalah 25

- 38 ton/ha (Hafsah, 2003). Perkiraan pada analisis berdasarkan bobot/ tanaman, maka ubi kayu di kebun memiliki potensi hasil yang lebih tinggi. Pada kenyataan di lapangan, hasil yang diperoleh jauh lebih rendah dari hasil analisis. Dari hasil panen diperoleh produktivitas blok B2, B3, B14 dan B15 secara berturut-turut adalah 23.85 ton/ha, 29.29 ton/ha, 22.90 ton/ha, dan 18.79 ton/ha.

Tabel 8. Bobot umbi ubi kayu/tanaman (kg)

\begin{tabular}{ccccc}
\hline No & $\begin{array}{c}\text { Blok B2 } \\
(\mathrm{kg})\end{array}$ & $\begin{array}{c}\text { Blok B3 } \\
(\mathrm{kg})\end{array}$ & $\begin{array}{c}\text { Blok B14 } \\
(\mathrm{kg})\end{array}$ & $\begin{array}{c}\text { Blok B15 } \\
(\mathrm{kg})\end{array}$ \\
\hline 1 & 1.60 & 7.10 & 2.50 & 5.86 \\
2 & 2.65 & 4.60 & 5.60 & 4.40 \\
3 & 3.60 & 2.55 & 4.20 & 5.90 \\
4 & 4.30 & 1.56 & 3.00 & 4.00 \\
5 & 5.50 & 2.60 & 3.85 & 2.25 \\
6 & 1.10 & 5.62 & 2.90 & 2.53 \\
7 & 4.55 & 4.05 & 2.84 & 2.60 \\
8 & 2.53 & 5.15 & 3.18 & 4.03 \\
9 & 2.85 & 1.30 & 3.50 & 3.86 \\
10 & 2.14 & 3.25 & 1.00 & 2.49 \\
11 & 4.07 & 3.82 & 4.20 & 1.63 \\
12 & 1.03 & 2.20 & 3.20 & 2.78 \\
13 & 5.16 & 1.86 & 2.43 & 3.24 \\
14 & 3.35 & 5.75 & 2.60 & 2.77 \\
15 & 1.70 & 5.10 & 1.95 & 1.04 \\
\hline Rata-rata & 3.08 & 3.77 & 3.13 & 3.29 \\
\hline
\end{tabular}

Blok A20 memiliki produktivitas yang lebih tinggi dibanding blok yang lainnya, yaitu 30.01 ton/ha. Pada kondisi di lapangan, pada blok A20 tidak terdapat area yang tergenang air, tanah lebih subur, dan dipanen lebih awal dibanding blok yang lainnya. Sedangkan blok B9 memiliki produktivitas yang paling rendah, yaitu 14.75 ton/ha. Pada blok B9 terdapat masalah busuk umbi dan banyak area yang tergenang air sehingga banyak ubi kayu yang mati.

Produktivitas yang tidak mencapai potensi hasil varietas Kasetsart juga disebabkan kesuburan tanah. Tingkat kesuburan tanah termasuk sangat rendah sampai dengan rendah. Pada kondisi tanah yang kurang subur sebaiknya jarak tanam yang digunakan yaitu $100 \times 66 \mathrm{~cm}$ atau $125 \times 64 \mathrm{~cm}$ dengan populasi per hektarnya antara 12500 sampai dengan 15000 tanaman. Dengan jarak tanam yang terlalu rapat mengakibatkan hasil ubi kayu menjadi menurun karena populasi dan jarak tanam yang optimal berpengaruh terhadap pemaksimalan pemanfaatan hara dan cahaya surya (matahari) oleh tanaman (Wargiono et al., 2006).

Rata-rata produktivitas ubi kayu untuk petani mitra lebih tinggi. Produktivitas rata-rata ubi kayu petani mitra mencapai 23.73 ton/ha. Namun, produktivitas rata-rata dari petani mitra belum mencapai potensi hasil dari varietas Kasetsart. Rendahnya produktivitas pada petani disebabkan berberapa faktor seperti lahan yang kurang subur karena ditanami secara terusmenerus, jarak tanam, (ubi kayu tidak dibudidayakan dengan baik (gulma dibiarkan samapai tinggi, penggunaan pupuk yang disesuaikan dengan kondisi ekonomi), adanya petani mitra yang tidak melakukan leles, dan terjadinya masalah busuk umbi.

Pasca panen di kebun. Sebagian brangkasan dari ubi kayu di kebun dikembalikan ke tanah dan sebagian batang digunakan untuk bibit sedangkan petani mitra pada umumnya menggunakan daun ubi kayu untuk makanan ternak, batang digunakan untuk bibit pada penanaman berikutnya. Sebagian petani juga menjual batang ubi kayu untuk bibit. Dengan demikian hanya sedikit sisa tanaman yang kembali ke tanah. Hal ini akan memepercepat penurunan kesuburan tanah.

Kebutuhan bahan baku SPMI. Ubi kayu yang telah dipanen dari kebun dan petani mitra akan diangkut ke pabrik. Dengan luasan ubi kayu kebun dan petani mitra, maka kebutuhan bahan baku tidak akan terpenuhi. Hasil panen ubi kayu petani mitra sendiri hanya dapat memenuhi $22.49 \%$ dari total kebutuhan minimum. Jika kebutuhan minimum bahan baku setiap hari 
sebanyak 700 ton ubi kayu dan jumlah hari kerja dalam satu bulan adalah 25 hari, maka dalam satu tahun dibutuhkan sebanyak 210000 ton ubi kayu. Jika rata-rata produktivitas ubi kayu adalah 22 ton/ha, maka diperlukan penambahan area penanaman seluas 5008 ha. Kurangnya bahan baku mengakibatkan adanya lapak-lapak dibeberapa wilayah.

Pasca panen di pabrik.

1. Lama bahan baku di lapangan. Penundaan pengolahan ubi kayu dapat menurunkan kandungan pati (Tengah at al., 1996). Menurunnya kadar pati disebabkan proses metabolisme dalam umbi ubi kayu yang berlangsung terus sehingga perombakan karbohidart/pati menjadi senyawa gula yang lebih sederhana tetap berlangsung, akibatnya akan terjadi penurunan kadar pati umbi (Soeharmadi, 1990). Unuk itu ubi kayu yang telah dipanen hendaknya langsung diolah. Pabrik akan mengolah ubi kayu apabila tercapai bobot 700 ton. Pada kenyataan di lapangan, bahan baku yang dipereleh lebih dari 700 ton. Pada musim panen ubi kayu yang tersedia banyak sehingga terjadinya penimbunan bahan baku di lapangan. Penimbunan bahan baku di lapangan diupayakan hanya sampai untuk pengolahan 3 hari untuk menghindari busuknya ubi kayu. Selain pada musim panen, penimbunan ubi kayu juga dapat terjadi karena adanya ganguan mesin, sehingga proses produksi tidak berjalan dengan lancar.

2. Pengukuran kadar aci. Pada saat dilakukan penimbangan, ubi kayu dari dalam angkutan diambil sebagian sampel $( \pm 5 \mathrm{~kg})$. Sampel ini digunakan untuk mengkur kadar Aci. Pengukuran kadar aci dilakukan untuk menetukan besarnya potongan yang akan diberikan. Untuk ubi kayu yang berasal dari kebun pengukuran kadar aci hanya dilakukan jika varietas yang ditanama diganti. Kadar aci ubi kayu kebun varietas Kasetsart adalah $24 \%$ sedangkan kadar aci untuk petani berkisar 10 $30 \%$. Kadar aci ubi kayu yang rendah disebabkan adanya pencampuran ubi kayu secara sengaja dan pemanenan ubi kayu dengan umur panen 7 bulan. Ubi kayu dengan umur 7 bulan belum memenuhi standar mutu karena ubi kayu yang dipanen pada umur 7 bulan memiliki kadar pati kurang dari 19\% sedangkan kadar pati untuk Kasetsart adalah 19 - $30 \%$. Ubi kayu yang biasa dicampur adalah varietas Kasetsart dengan varietas Thailand. Pada saat pengamatan tida terdapat ubi kayu yang dicampur sehingga kadar aci ubi kayu petani cukup bagus yaitu $24-28 \%$.
3. Penentuan rafaksi. Rafaksi adalah besarnya potongan yang diberikan pihak pabrik berdasarkan kondisi ubi kayu. Besarnya rafaksi dipengaruhi oleh beberapa faktor. Semakin muda umur panen, maka rafaksi yang diberikan akan semakin besar. Dalam hal ini, yang dimaksud panen muda adalah ubi kayu yang dipanen kurang dari 9 bulan. Semakin banyak benda asing (bonggol ubi kayu, tanah, dan batu) yang tercampur pada ubi kayu, maka rafaksi akan semakin besar. Penetuan rafaksi dilakukan pada saat ubi kayu dikeluarkan dari angkutan panen. Rafaksi untuk ubi kayu yang berasal dari kebun saat ini sebesar $5 \%$. Besarnya rafaksi berdasarkan kesepakatan kerja. Sedangkan rafaksi untuk petani mitra maupun petani buka mitra berbeda-beda. Rafaksi untuk petani mitra dan bukan petani mitra yaitu 5 - $30 \%$. Rafaksi sebesar 5\% sangat jarang terjadi karena kualitas ubi dari petani mitra dan petani sangat jarang sama dengan kualitas ubi kayu dari kebun. Rafaksi $30 \%$ juga sangat jarang terjadi. Rafaksi $30 \%$ hanya terjadi jika ubi kayu dipanen kurang dari 7 bulan, karena umbi kecil, banyak benda asing yang tercampur, dan jenis ubi kayu bukan Kasetsart. Besarnya rafaksi yang umum diberikan adalah $6-8 \%$.

\section{KESIMPULAN}

Manajemen panen dan pasca panen ubi kayu yang baik diperlukan dalam mengatasi masalah kualitas dan kuantitas pasokan bahan baku. Masalah panen dan pasca penen di kebun adalah penundaan umur panen, terbatasnya ketersediaan angkutan panen, selang waktu antara panen dan pelelesan yang terlalu lama, pengawasan panen tidak maksimal dan kurangnya tenaga kerja. Sedangkan masalah panen dan pasca panen di petani mitra adalah ubi kayu dipanen terlalu muda, kondisi jalan yang buruk, dan pengawasan yang kurang maksimal. Penundaan umur panen sampai 18 bulan tidak meningkatkan bobot panen ubi kayu. Semakin lama ubi kayu dibiarkan di area maka semakin besar losses, mencapai 5.9\%. Losses juga timbul akibat tidak dilakukannya pelelesan di kebun petani mitra mencapai 5\% dari total hasil panen. Ubi kayu hasil panen dari kebun dan petani mitra hanya mampu memenuhi $22.49 \%$ dari kebutuhan bahan baku minimum. Untuk itu diperlukan penambahan area seluas 5008 ha untuk memenuhi kebutuhan bahan baku pabrik. Rafaksi ubi kayu petani mitra berkisar 5\% - 30\%. 


\section{DAFTAR PUSTAKA}

Bank Indonesia. 2004. Pola Pembiayaan Usaha Kecil (Ppuk) Budidaya Ubi Kayu. Direktorat Kredit, BPR dan UMKM. Jakarta. 32 halaman.

Barrett, D. M., Damardjati, D. S. 1984. Peningkatan mutu hasil ubi kayu di Indonesia. [internet] [diunduh 05 Agust 2010]. Tersedia pada http://www.linkpdf.com.

Costa, Y. W. 2010. Memanfaatkan limbah ubi kayu menjadi kecap. [internet] [diunduh 15 Sept 2010]. Tersedia pada http://www.deptan.go.id.

[DEPTAN] Departemen Pertanian. 2007. Peluang pengembangan industri berbasis casava. [internet] [diunduh 15 Sept 2011]. Tersedia pada Deptan.go.id pengolahan ubi kayu.pdf.

Hafsah, M.J. 2003. Bisnis Ubikayu Indonesia. Jakarta (ID) : Pustaka Sinar Harapan. 263 hal.

Kasim, Y. 2009. Pemanfaatan pati ubi kayu dalam berbagai industri. [internet] [diunduh 01 Agust 2011]. Tersedia pada http://www.iptek.net.id.

Pusat Data dan Sistem Informasi Pertanian Kementerian Pertanian. 2011. Indikator Makro Sektor Pertanian. BltnMakro. Vol. $5(8): 7$.

Puspitasari, A. D. 2009. Wilayah kesesuaian untuk tanaman ubi kayu di kabupaten lampung tengah. [internet] [diunduh 01 Agust 2010]. Tersedia pada http://www.scribd.com.

Sulaiman, Y. 2007. Manajemen Pemanenan Kelapa Sawit (Elaesis guinansis jaqc.) dan Aspek Taksasi Produksi di PT. Sentosa Mulia Bahagia, Musi Bayuasin, Sumatera Selatan. [Skripsi]. Departemen Agronomi dan Hortikultura. Fakultas Pertanian. Institut Pertanian Bogor. Bogor. 86 halaman.

Soeharmadi, 1990. Usaha meningkatkan daya simpan ubi segar. [internet] [diunduh 15 Sept 2010]. Tersedia pada litbang.go.id.

Tengah, I.G.P., Mulyani, S., Ina, P.T., Ekawati, I.G.A., Utama, I.B.D. 1996. Pengaruh penundaan pengolahan ubi kayu menjadi gaplek terhadap mutu pelet yang dihasilkan. Majalah Ilmiah Teknologi Pertanian. Vol. 2(1) : 21-25.

Tongglum, A., P. Suriyanapan, R.H. Howeler. 2001. Cassava Agronomy Research and Adoption of Improved Practices in Thailand, Major Achievement During the Past 35 years. Proc. of the Sixth Regional Workshop, Cassava's Potential in Asia in the 21st Century: Present Situation and Future Research and Development Needs. Centre of Tropical Agriculture (CIAT). Ho Chi Minch City. 228-258.

Wargiono, J., A. Hasanuddin, Suyamto. 2006. Teknologi Produksi Ubikayu Mendukung Industri Bioethanol. Puslitbangtan Bogor; 42halaman. 